\title{
A Phase II trial of axitinib in patients with various histologic subtypes of advanced thyroid cancer: long-term outcomes and pharmacokinetic/pharmacodynamic analyses
}

\author{
E. E. W. Cohen - M. Tortorici $\cdot$ S. Kim - A. Ingrosso • \\ Y. K. Pithavala $\cdot$ P. Bycott
}

Received: 9 December 2013 / Accepted: 3 October 2014 / Published online: 15 October 2014

(C) The Author(s) 2014. This article is published with open access at Springerlink.com

\begin{abstract}
Purpose Axitinib, a potent and selective second-generation inhibitor of vascular endothelial growth factor receptors, has shown activity in advanced thyroid cancer in a Phase II study. We report updated overall survival and pharmacokinetic/pharmacodynamic (PK/PD) analyses from the study.

Methods Patients $(N=60)$ with advanced thyroid cancer of any histology for whom iodine-131 ( $\left.{ }^{131} \mathrm{I}\right)$ failed to control the disease or ${ }^{131}$ I was not appropriate therapy were administered axitinib $5 \mathrm{mg}$ twice daily. Objective response rate (primary endpoint), duration of response,
\end{abstract}

Electronic supplementary material The online version of this article (doi:10.1007/s00280-014-2604-8) contains supplementary material, which is available to authorized users.

\section{E. E. W. Cohen $(\bowtie)$}

Division of Biological Sciences, University of Chicago, Chicago,

IL, USA

e-mail: ecohen@ucsd.edu

Present Address:

E. E. W. Cohen

Department of Medicine, University of California San Diego

Moores Cancer Center, 3855 Health Sciences Drive, La Jolla, CA

92093, USA

\section{Tortorici}

Pfizer Global Research and Development, Pfizer Inc.,

Collegeville, PA, USA

S. Kim · P. Bycott

Clinical Development, Pfizer Oncology, San Diego, CA, USA

A. Ingrosso

Clinical Development, Pfizer Oncology, Milan, Italy

Y. K. Pithavala

Clinical Pharmacology, Pfizer Oncology, San Diego, CA, USA progression-free survival, overall survival, safety, and PK/ PD relationships were assessed.

Results Objective response rate was $38 \%$ [23 partial responses; $95 \%$ confidence interval (CI) 26-52], and $18(30 \%)$ patients had stable disease lasting $\geq 16$ weeks. Responses occurred in all histologic subtypes. With median follow-up of 34 months (95\% CI 32-37), median overall survival was 35 months (95\% CI 19-not estimable), median progression-free survival was 15 months (95\% CI 10-20), and median duration of response was 21 months (95 \% CI 13-46). Most common Grade 3/4 treatmentrelated adverse events included hypertension (13\%), proteinuria $(8 \%)$, diarrhea $(7 \%)$, weight decrease $(7 \%)$, and fatigue $(5 \%)$. PK/PD analyses revealed trends toward greater tumor size reduction and response probability with higher axitinib plasma exposures.

Conclusions Axitinib appears active and well tolerated in patients with various histologic subtypes of advanced thyroid cancer, demonstrating durable responses and long overall survival. Axitinib may be useful for the treatment of advanced thyroid cancer.

Keywords Axitinib - Iodine-refractory .

Pharmacokinetic $\cdot$ Pharmacodynamic $\cdot$ Thyroid cancer

\section{Introduction}

Thyroid cancer was diagnosed in approximately 212,000 individuals worldwide and resulted in about 35,000 deaths in 2008 [1]. Its incidence has increased, on average, by $58 \%$ in most populations [2]. Despite its rising incidence, thyroid cancer mortality in the European Union has declined [3]. Survival is stage-dependent, with a 5-year relative survival rate of $57.3 \%$ for distant disease [4]. 
Thyroid tumors have elevated levels of vascular endothelial growth factor (VEGF) compared with normal thyroid tissue [5], suggesting the VEGF pathway as an appropriate therapeutic target. Several tyrosine kinase inhibitors (TKIs) targeting the VEGF pathway (e.g., sorafenib [6-11], sunitinib [12-14], axitinib [15, 16], vandetanib [17, 18], pazopanib [19], motesanib [20, 21], cabozantinib [22-24], and lenvatinib [25]) have been evaluated in patients with advanced thyroid cancer.

Axitinib, a potent and selective second-generation inhibitor of VEGF receptors (VEGFRs) [26], is approved in the USA, European Union, and elsewhere for the treatment of advanced renal cell carcinoma (RCC) after failure of prior systemic therapy [27]. The activity of axitinib was previously reported in a Phase II trial of patients with various histologic subtypes of advanced thyroid cancer in whom iodine-131 $\left({ }^{131} \mathrm{I}\right)$ failed to control the disease or ${ }^{131} \mathrm{I}$ was not appropriate therapy [16]. The final clinical results with long-term outcomes, including updated overall survival (OS), and pharmacokinetic/pharmacodynamic (PK/PD) analyses from this trial are reported here.

\section{Materials and methods}

Study design

The primary objective of this Phase II study in patients with advanced thyroid cancer was to determine the activity of axitinib as measured by investigator-assessed overall objective response rate (ORR) per Response Evaluation Criteria in Solid Tumors (RECIST, v. 1.0) [28]. Complete response (CR) or partial response (PR) required confirmation at least 4 weeks after the first observation. The secondary objectives were to determine OS, progression-free survival (PFS), duration of response, and safety; obtain blood samples for population PK analyses; and explore relationships between clinical response and plasma-soluble proteins (i.e., VEGF and soluble VEGFR2 [sVEGFR2]).

This study was conducted in accordance with the Declaration of Helsinki, International Conference on Harmonization Guideline for Good Clinical Practice, study protocol, and all applicable local regulatory requirements and laws. Each participant provided written informed consent prior to inclusion in the study and agreed to comply with the study protocol. Study protocol and informed consent forms were approved by an institutional review board or independent ethics committee. The trial is registered on ClinicalTrials. gov (NCT00094055).

Patients and assessments

Key patient inclusion/exclusion criteria and assessments were previously described [16]. Briefly, the trial enrolled adults with advanced thyroid cancer of any histology for whom ${ }^{131}$ I failed to control the disease or ${ }^{131}$ I was not appropriate therapy. Patients had Eastern Cooperative Oncology Group performance status 0 or 1 , and at least one RECIST-defined target lesion not previously externally irradiated. Patients with uncontrolled hypertension [i.e., baseline blood pressure (BP) $>140 / 90 \mathrm{~mm} \mathrm{Hg}$ ] were ineligible; antihypertensive medications were permitted. Prior treatment with antiangiogenic agents was not permitted.

\section{Treatments}

Axitinib was administered orally at a starting dose of $5 \mathrm{mg}$ twice daily without food or drink, other than water, for $2 \mathrm{~h}$ before and after each dose. Patients tolerating axitinib without treatment-related adverse events (AEs) Grade $>1$ according to the Common Terminology Criteria for Adverse Events (CTCAE, v3.0) [29] for any 8-week period were permitted a $20 \%$ dose increase, unless responding to therapy. Patients developing subjectively intolerable, treatment-related Grade 2 AEs (except alopecia) uncontrolled by supportive treatment had axitinib interrupted and restarted at the same dose after resolution to Grade $\leq 1$ or baseline. If resolution did not occur within 4 weeks, axitinib was discontinued.

Patients developing treatment-related Grade 3/4 nonhematologic AEs (except for alopecia) or treatment-related Grade 4 hematologic AEs uncontrolled by supportive treatment had axitinib interrupted. Upon adequate recovery to Grade $\leq 1$ or baseline, treatment was resumed at a $20 \%$ lower dose. If resolution did not occur within 4 weeks, axitinib was discontinued. Patients with recurring subjectively intolerable toxicity resumed axitinib at a $20 \%$ lower dose upon adequate recovery. The previous report [16] specified a slightly different dose-modification schema that is more consistent with the axitinib prescribing information [27]. Axitinib was continued until disease progression, unacceptable toxicity, or consent withdrawal. Subsequent therapy was at the investigator's discretion.

Plasma pharmacokinetic samples and analysis

Samples ( $7 \mathrm{~mL}$ of whole blood) for population PK analysis were collected $15 \mathrm{~min}$ before and 1-2 $\mathrm{h}$ after the morning dose of axitinib (taken in clinic) on days 1 and 29 and every 8 weeks thereafter. Patients were required to take axitinib uninterrupted for $\geq 3$ days before PK blood sample collection (not applicable on day 1).

Axitinib plasma concentrations were measured using validated high-performance liquid chromatography with tandem mass spectrometric detection (Charles River Laboratory Preclinical Services, Shrewsbury, MA, USA) [3032]. Following population $P K$ analysis, individual post hoc 
area under the plasma concentration-time curve at steady state $\left(\mathrm{AUC}_{\mathrm{ss}}\right)$ was calculated as follows:

$\mathrm{AUC}_{\mathrm{ss}-\text { study }}=$ average total daily dose during entire time on study/CL

and

$\mathrm{AUC}_{\text {ss-cycle1 }}=$ average total daily dose during cycle $1 / \mathrm{CL}$

where CL is systemic plasma clearance for axitinib (individual post hoc clearance estimated from population PK analysis), $\mathrm{AUC}_{\mathrm{ss}-\text { study }}$ is the average $\mathrm{AUC}_{\mathrm{ss}}$ across entire time on study, and $\mathrm{AUC}_{\mathrm{ss}-\mathrm{cycle} 1}$ is the average $\mathrm{AUC}_{\mathrm{ss}}$ during cycle 1 .

Plasma-soluble protein biomarkers

Plasma samples for measurement of VEGF and sVEGFR2 levels were collected on day 1 and every 8 weeks thereafter. Details of the bioanalytical methodology for measurement of plasma-soluble proteins were previously described [16].

\section{Statistical analysis}

Sample size was based on a two-stage Simon minimax design [33] to evaluate the null hypothesis that the true ORR with axitinib was $\leq 5 \%$ and the alternative hypothesis that ORR was $\geq 20 \%$, with type I $(\alpha)$ and type II ( $\beta$ ) error rates of 0.10 . Target accrual was 18 patients in stage I, with 14 additional patients in stage II if one or more confirmed responses were observed. Twenty-eight additional patients (total of 60) were treated to gain additional safety and activity information. Response rate was summarized, and confidence interval (CI) calculated using a method based on binomial distribution. Kaplan-Meier methods were used to estimate the median PFS, duration of response, and OS; corresponding CIs were calculated. Thirteen patients continued axitinib in an ongoing extension, study A4061008 (ClinicalTrials.gov, NCT00828919), in which only safety data were collected. Efficacy and safety data reported here for those 13 patients were based on data collected from this original trial.

Initial relationships between axitinib exposure and change in tumor size, as measured by sum of longest diameter (SLD) of target lesions, were explored using a simple linear regression analysis. Patients were stratified by axitinib $\mathrm{AUC}_{\mathrm{ss}}$ (higher or lower than population median), and change from baseline in soluble proteins was compared using descriptive statistics. Patients were grouped into quartiles according to change from baseline in soluble proteins, and the proportion of RECIST responders ( \pm standard deviation) was assessed.

Logistic regression for probability of PR was performed. The probability of achieving PR was assessed as a function of $\mathrm{AUC}_{\mathrm{ss}-\mathrm{cycle} 1}$. Odds ratio per $1 \mathrm{ng} \mathrm{h} / \mathrm{mL}$ change in AUC was calculated as:

odds ratio $=\exp ^{\beta}$

where $\beta$ was the logistic regression slope coefficient.

\section{Results}

Patients and treatment

Baseline characteristics and demographics for the 60 patients enrolled were previously reported [16]. Briefly, median age was 59 years (range 26-84) and $78 \%$ of patients were white; histologic subtypes are shown in Table 1 . The majority $(97 \%)$ of patients received prior treatment; however, patients had not received prior antiangiogenic agents. All patients discontinued the study: 20 experienced insufficient clinical response; 14 planned to enroll in the ongoing extension study A4061008 (ClinicalTrials.gov, NCT00828919); 11 experienced non-fatal AEs; nine refused further participation; four died due to cardiorespiratory arrest, multiorgan failure, respiratory failure, or pneumonia; and two were lost to follow-up. One patient planning to enroll in the extension study had an optical malignancy and did not participate.

Median duration of axitinib exposure was 11 months (range 0.2-47); 30 patients remained on treatment for at least 1 year. Median total daily dose of axitinib was $9 \mathrm{mg}$ (range $2-15 \mathrm{mg}$ ). The axitinib dose was increased ( $>5 \mathrm{mg}$ twice daily) in 24 patients eligible for dose titration, half of whom had a subsequent dose reduction. Another 24 patients had dose reductions.

\section{Clinical activity}

Response assessments were unavailable for 14 patients because of missing post-baseline scans or indeterminate results (i.e., availability of only one or two post-baseline scans, which did not allow confirmation of either PR or duration of stable disease $\geq 16$ weeks). For purposes of calculating ORR, they were considered non-responders. The investigator-assessed overall ORR was $38 \%(95 \% \mathrm{CI}$ 26-52); no patient had CR, 23 had PR, and 18 (30\%) had stable disease lasting $\geq 16$ weeks. Of the 18 patients with stable disease, 17 had stable disease lasting $\geq 30$ weeks. Compared with our initial ORR analysis [16], five additional patients had confirmed PR with long-term followup. One patient with PR on day 600 had $22 \%$ reduction in tumor size beginning on day 300 , and another patient with PR on day 835 had $12 \%$ reduction in tumor size beginning on day 166 that increased to $29 \%$ on day 499. Responses occurred in all histologic subtypes (Table 1). 
Table 1 Investigator-assessed objective response to axitinib: overall and by histologic subtype

\begin{tabular}{|c|c|c|c|c|c|c|}
\hline & $\begin{array}{l}\text { Complete response } \\
n(\%)\end{array}$ & $\begin{array}{l}\text { Partial response } \\
n(\%)\end{array}$ & $\begin{array}{l}\text { Stable disease }^{\mathrm{a}} \\
n(\%)\end{array}$ & $\begin{array}{l}\text { Progressive disease } \\
n(\%)\end{array}$ & $\begin{array}{l}\text { Indeterminate } \\
n(\%)\end{array}$ & $\begin{array}{l}\text { Missing } \\
n(\%)\end{array}$ \\
\hline All patients $(N=60)$ & 0 & $23(38)^{\mathrm{b}}$ & $18(30)$ & $5(8)$ & $9(15)$ & $5(8)$ \\
\hline \multicolumn{7}{|l|}{ Histologic subtype } \\
\hline Papillary $(n=30)$ & 0 & $10(33)$ & $10(33)$ & $3(10)$ & $4(13)$ & $3(10)$ \\
\hline Follicular $(n=15)^{\mathrm{c}}$ & 0 & $9(60)$ & $4(27)$ & $1(7)$ & $1(7)$ & 0 \\
\hline Medullary $(n=11)$ & 0 & $2(18)$ & $3(27)$ & 0 & $4(36)$ & $2(18)$ \\
\hline Anaplastic $(n=2)$ & 0 & $1(50)$ & 0 & $1(50)$ & 0 & 0 \\
\hline Other $(n=2)$ & 0 & $1(50)^{\mathrm{d}}$ & $1(50)^{\mathrm{e}}$ & 0 & 0 & 0 \\
\hline
\end{tabular}

${ }^{\text {a }}$ Lasting $\geq 16$ weeks. Of the 18 patients with stable disease $\geq 16$ weeks, 17 had stable disease $\geq 30$ weeks

b $95 \%$ confidence interval 26-52

c 11 patients had the Hürthle cell variant

${ }^{\mathrm{d}}$ Insular

e Neuroendocrine

With an estimated median follow-up for survival of 34 months (95\% CI 32-37), disease progression or death had occurred in 37 (62\%) patients. These updated results, accounting for additional follow-up, are based on the final locked and clean database. These data were preliminarily reported [16], based on an active database and shorter follow-up of 16.6 months (95\% CI 15.0-21.2). In the final analysis, investigator-assessed median PFS was 15 months (95\% CI 10-20; Fig. 1a), median duration of response was 21 months (95\% CI 13-46; Fig. 1b), and median OS was 35 months (95\% CI 19 months-not estimable). Figure 1c illustrates OS according to histology.

\section{Safety}

All-grade, treatment-related AEs (Table 2) occurred in 56 (93\%) patients; the most frequently reported AEs included diarrhea $(63 \%)$, fatigue ( $55 \%$ ), nausea ( $45 \%$ ), and hypertension (42\%). Grade 3/4 treatment-related AEs occurred in $21(35 \%)$ patients; the most common were hypertension $(13 \%)$, proteinuria $(8 \%)$, diarrhea $(7 \%)$, weight decrease $(7 \%)$, and fatigue $(5 \%)$. Five $(8 \%)$ patients experienced a total of six treatment-related Grade 4 AEs: reversible posterior leukoencephalopathy syndrome (RPLS) and hypertension $(n=1)$, proteinuria $(n=2)$, cerebrovascular accident $(n=1)$, and airway obstruction $(n=1)$. No Grade 5 (fatal) treatment-related AE was reported. Eight patients experienced 18 treatment-related serious AEs (SAEs): RPLS, mental status changes, and hypertension $(n=1)$; cerebrovascular accident and headache $(n=1)$; abdominal pain $(n=1)$; hypertension $(n=1)$; conduction disorder, diarrhea, nausea, vomiting, chest pain, and dehydration $(n=1)$; atrial fibrillation $(n=1)$; granuloma, airway obstruction, and respiratory tract hemorrhage $(n=1)$; and weakness $(n=1)$. Hypertension $(n=2)$ was the only treatment-related SAE experienced by more than one patient.

Four treatment-related AEs led to permanent axitinib discontinuation: headache (Grade 1), cerebrovascular accident (Grade 4), proteinuria (Grade 2), and weakness (Grade unknown). AEs led to axitinib dose reductions in 25 (42\%) patients. Diarrhea $(10 \%)$, fatigue $(10 \%)$, hypertension (7\%), and palmar-plantar erythrodysesthesia $(5 \%)$ were most frequently associated with dose reductions. Hypertension was managed with antihypertensive medication. No patients discontinued the study because of hypertension; BP elevations were generally resolved by the next assessment.

Pharmacokinetic/pharmacodynamic analyses

In all, 49 of 60 patients had adequate PK data to calculate post hoc $\mathrm{AUC}_{\mathrm{ss}}$ and were included in the PK/PD analyses. Greater reduction in tumor size (Fig. 2), assessed by maximum percent change from baseline in SLD of target lesions, was seen with increasing axitinib $\mathrm{AUC}_{\mathrm{ss}}$ cycle1 $(r=0.332 ; P=0.0134)$ and $\mathrm{AUC}_{\mathrm{ss}-\text { study }}(r=0.273$; $P=0.0523)$. As a measure of inherent axitinib exposure (i.e., before dose titration that could occur at or beyond 8 weeks), $\mathrm{AUC}_{\text {ss-cycle1 }}$ was used as a measure of drug exposure in individual patients for the remaining PK/PD analyses. Figure 3 provides a comparison of steady-state plasma exposures in patients who had PR (denoted at 1.0 on the $y$-axis) versus those who did not have PR (denoted at zero on the $y$-axis). These raw data were subjected to logistic regression to obtain the overlaid curve, which describes the probability of having PR as a function of axitinib plasma exposure. This analysis indicated that patients with higher axitinib plasma exposure $\left(\mathrm{AUC}_{\text {ss-cycle1 }}\right)$ had a greater likelihood of obtaining PR. 

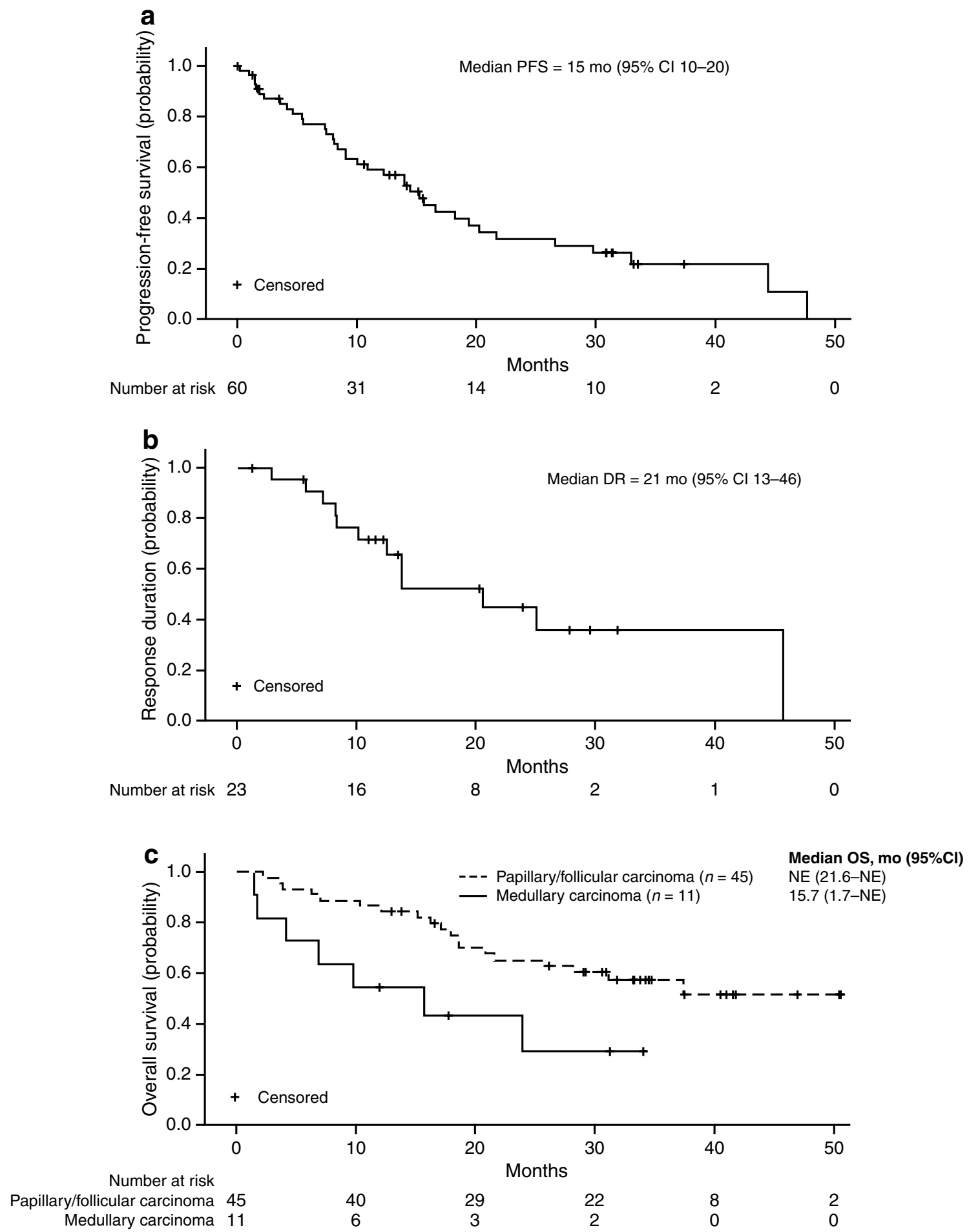

Fig. 1 Kaplan-Meier curves for a investigator-assessed PFS; b investigator-assessed duration of response (DR) among responders; and $\mathbf{c}$ overall survival (OS) stratified by histologic subtype. Data for PFS, DR, and OS were not collected in the axitinib extension study; therefore, results for the 13 patients who rolled over to the extension study were based on data collected from the original trial. $C I$ confidence interval, $N E$ non-estimable 
Table 2 Most common treatment-related adverse events

\begin{tabular}{lll}
\hline Adverse event $^{\mathrm{a}}$ & $\begin{array}{l}\text { All grades } \\
n(\%)\end{array}$ & $\begin{array}{l}\text { Grade 3/4 } \\
n(\%)\end{array}$ \\
\hline Any treatment-related AE & $56(93)$ & $21(35)$ \\
Diarrhea & $38(63)$ & $4(7)$ \\
Fatigue & $33(55)$ & $3(5)$ \\
Nausea & $27(45)$ & $1(2)$ \\
Hypertension & $25(42)$ & $8(13)$ \\
Weight decrease & $19(32)$ & $4(7)$ \\
Anorexia & $18(30)$ & 0 \\
Stomatitis & $18(30)$ & 0 \\
Dyspepsia & $17(28)$ & 0 \\
Headache & $17(28)$ & $2(3)$ \\
Mucosal inflammation & $15(25)$ & 0 \\
Proteinuria & $15(25)$ & $5(8)$ \\
Palmar-plantar erythrodysesthesia syndrome & $13(22)$ & $1(2)$ \\
Rash & $13(22)$ & 0 \\
Dysgeusia & $12(20)$ & 0 \\
Hoarseness & $12(20)$ & 0 \\
\hline
\end{tabular}

$A E$ adverse event

a Reported in $\geq 20 \%$ of patients

Axitinib was previously reported to lead to a 2.8fold increase in mean VEGF and $32 \%$ decrease in mean sVEGFR2 concentrations that plateau by week 12 [16]. In the current analysis, patients with exposure to axitinib that was equal to or greater than median $\mathrm{AUC}_{\text {ss-cycle1 }}$ had greater median VEGF increases and sVEGFR2 decreases (Fig. 4a). When grouped into quartiles according to percent change from baseline in VEGF and sVEGFR2 concentrations, higher proportions of responses were observed in patients with the greatest increases from baseline in VEGF and those with the greatest decreases from baseline sVEGFR2 (Fig. 4b). When stratified by the length of time patients received axitinib ( $\geq 1$ vs. $<1$ year), no differences were observed in median VEGF increases or sVEGFR2 decreases from baseline (data not shown).

\section{Discussion}

A $38 \%$ ORR and 21-month median duration of response for axitinib $5 \mathrm{mg}$ twice daily is reported in patients with advanced thyroid cancer. Although the sample size was too small for definitive assessment, follicular histology appeared to be most responsive to axitinib (Table 1). Stable disease lasting $\geq 16$ weeks, as defined by the protocol, occurred in an additional 18 (30\%) patients; however, 17 of those patients had stable disease lasting $\geq 30$ weeks. These translated into 15-month median PFS and 35-month median OS. Results from another Phase II trial of axitinib in patients $(N=52)$ with ${ }^{131}$ I-refractory advanced thyroid cancer demonstrated a comparable $35 \%$ ORR, 16.1-month median PFS, and 27.2-month median OS [15]. These two trials consistently demonstrated that axitinib has activity in the treatment of advanced thyroid cancer.

Since documented disease progression was not required prior to enrollment in this trial, PFS and OS data may be difficult to interpret in light of the natural history of metastatic thyroid cancer. Several randomized placebo-controlled Phase III trials evaluating VEGFR TKIs have now been conducted in patients with advanced thyroid cancer $[11,17,24]$. Patients receiving placebo in those trials had median PFS of 4 months [24] versus 19.3 months [17] for medullary thyroid cancer (MTC) with versus without progressive disease at study entry. Likewise, patients with progressive differentiated thyroid cancer (DTC) who received placebo had median PFS of 5.8 months [11]. In a randomized placebo-controlled Phase II trial, 16 (22\%) of 73 patients with DTC who received placebo had stable disease for a period of 12 months [18]. Whereas median OS has not been reported from these placebo-controlled trials, the survival analyses may be confounded by crossover to active treatment. Several single-arm Phase II trials have evaluated VEGFR TKIs [6-10, 12-14, 19-21, 25] for the treatment of advanced thyroid cancer (summarized in Online Resource 1). Only a few trials have reported median OS in patients treated with sorafenib: 23 and 38 months in non-progressive papillary thyroid cancer that was chemotherapy-naïve or previously treated with chemotherapy [7], respectively, and 35 months in progressive DTC [10].

The National Comprehensive Cancer Network 2013 Clinical Practice Guidelines [34] suggest consideration of systemic therapy with small molecule kinase inhibitors for clinically progressive or symptomatic metastatic ${ }^{131}$ I-refractory DTC. Additionally, European Society for Medical Oncology 2012 Clinical Practice Guidelines [35] recommend enrollment in clinical trials with TKIs for patients with metastatic DTC. Results from the current study suggest that axitinib may be a potential treatment option for ${ }^{131}$ I-refractory advanced DTC that is progressive or symptomatic. In long-term follow-up, the AE profile for axitinib was similar to previously reported results [16], thus confirming axitinib is well tolerated, with manageable toxicities.

The results reported here suggest there is an increased likelihood of an objective response in patients with the greatest VEGF increases and sVEGFR2 decreases; however, due to the considerable overlap observed in proportions of responders and change in VEGF/sVEGFR2 quartiles, these may not be optimal biomarkers to predict response to axitinib. A previous study also suggested that changes in sVEGFR2 levels after initiation of motesanib might predict response in patients with metastatic DTC 
Fig. 2 Maximum percent change from baseline observed at any point during the study in the sum of longest diameter (SLD) of target lesions relative to axitinib area under the plasma concentration-time curve at steady-state $\left(\mathrm{AUC}_{\mathrm{ss}}\right)$ during a cycle $1\left(\mathrm{AUC}_{\text {ss-cycle } 1}\right)$ and $\mathbf{b}$ the entire time on study $\left(\mathrm{AUC}_{\mathrm{ss}-\text { study }}\right)$; although no patients in the study had a RECIST-defined complete response, two patients had target lesions that became unmeasurable during axitinib treatment $(-100 \%$ change $)$
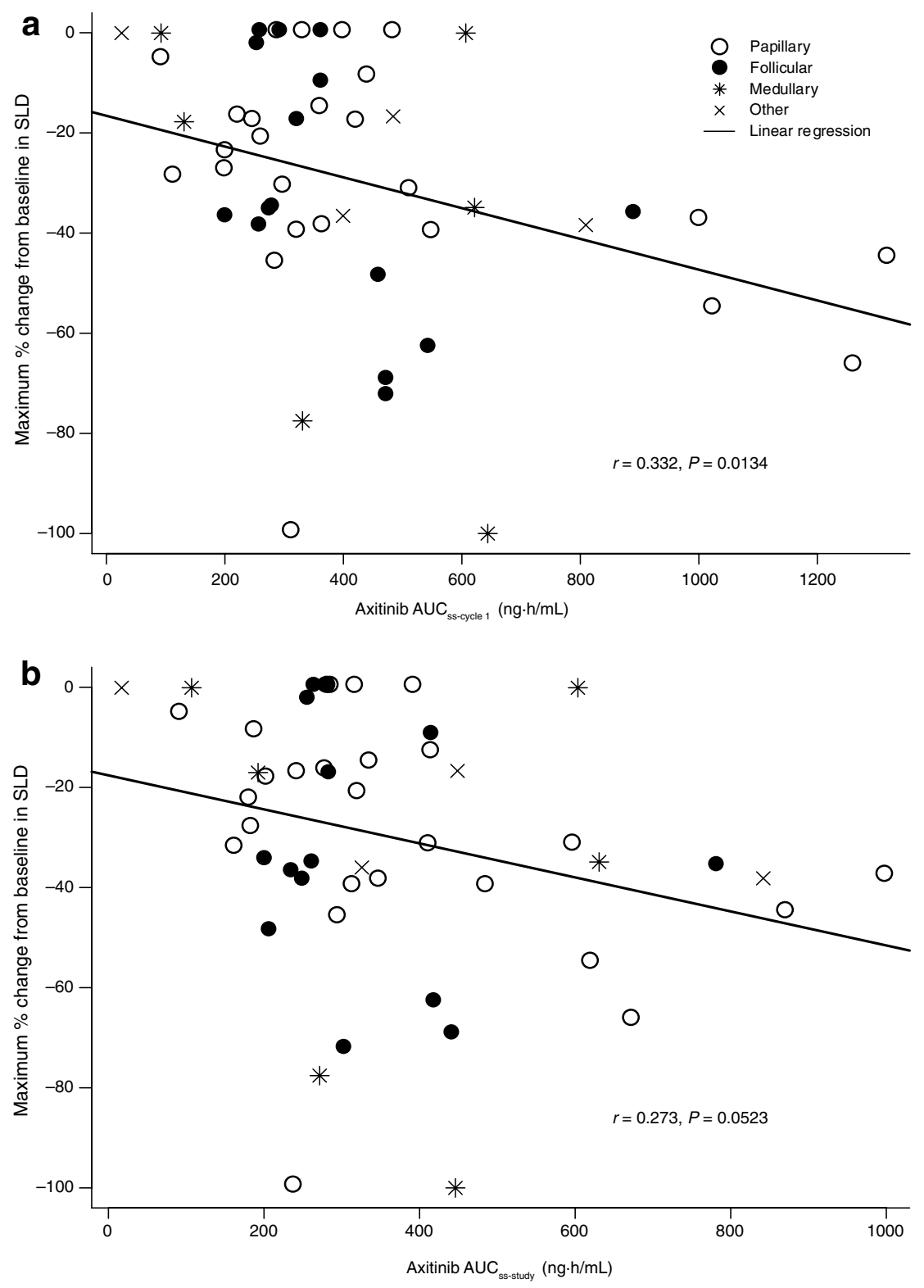

or MTC [36]. In the current study, patients with higher axitinib $\mathrm{AUC}_{\mathrm{ss}-\mathrm{cycle} 1}$, a measure of inherent axitinib exposure, had greater reduction in tumor size, probability of $\mathrm{PR}$, and greater median VEGF increases and sVEGFR decreases from baseline. In patients with metastatic RCC, greater axitinib exposure has also been associated with a higher ORR and longer PFS and OS [37]. Other investigators have conducted PK/PD analyses in patients with thyroid cancer. For example, motesanib $\mathrm{AUC}_{\mathrm{ss}}$ was a better predictor of response than dose [38]. Also, maximum pazopanib plasma concentration during the first treatment cycle correlated with maximum change in tumor size and was significantly higher in patients who achieved responses [19].
Limitations of the present trial included the number of patients with indeterminate or missing response assessments $(n=14)$, and the lack of control group and independent radiology review of response. Additionally, results for the 13 patients who continued axitinib for long periods of time in the extension study were based on data collected from this original trial. The extension study is ongoing and as of the cutoff date of June 1, 2012, duration of treatment ranged from 2.6 to 7.5 years in eight patients no longer receiving axitinib and from 6.2 to 7.4 years in five patients still receiving axitinib. Although $\mathrm{AE}$ data for long-term axitinib in the extension study were not yet available, five patients still on treatment were receiving total daily axitinib doses of 6-12 mg (data on file; Pfizer Inc, New York, NY, USA). 


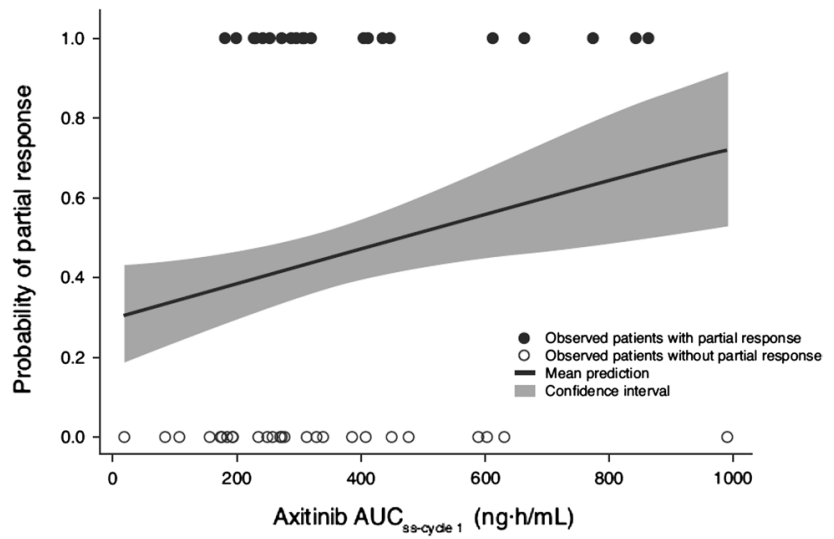

Fig. 3 Logistic regression analysis of probability of an investigatorassessed partial response relative to axitinib area under the plasma concentration-time curve at steady-state during cycle $1\left(\mathrm{AUC}_{\mathrm{ss}-\mathrm{cycle} 1}\right)$
In conclusion, axitinib appears to be active in various histologic subtypes of advanced thyroid cancer, as evidenced by a high ORR and long median duration of response, PFS, and OS. A limited number of patients with anaplastic histology $(n=2)$ were enrolled, making definitive conclusions in this subtype impossible. Axitinib also demonstrated a generally favorable safety profile. Moreover, greater axitinib exposure was associated with favorable differences in biomarkers and reduction in tumor size. PK/PD analyses suggest that patients with higher axitinib exposure were more likely to achieve PR, thereby providing further rationale for dose increases in patients who tolerate the starting dose of $5 \mathrm{mg}$ twice daily without elevated BP. Overall, these data suggest axitinib may be useful in the treatment of ${ }^{131} \mathrm{I}$-refractory advanced thyroid cancer, and individualized dose titration based on tolerability and
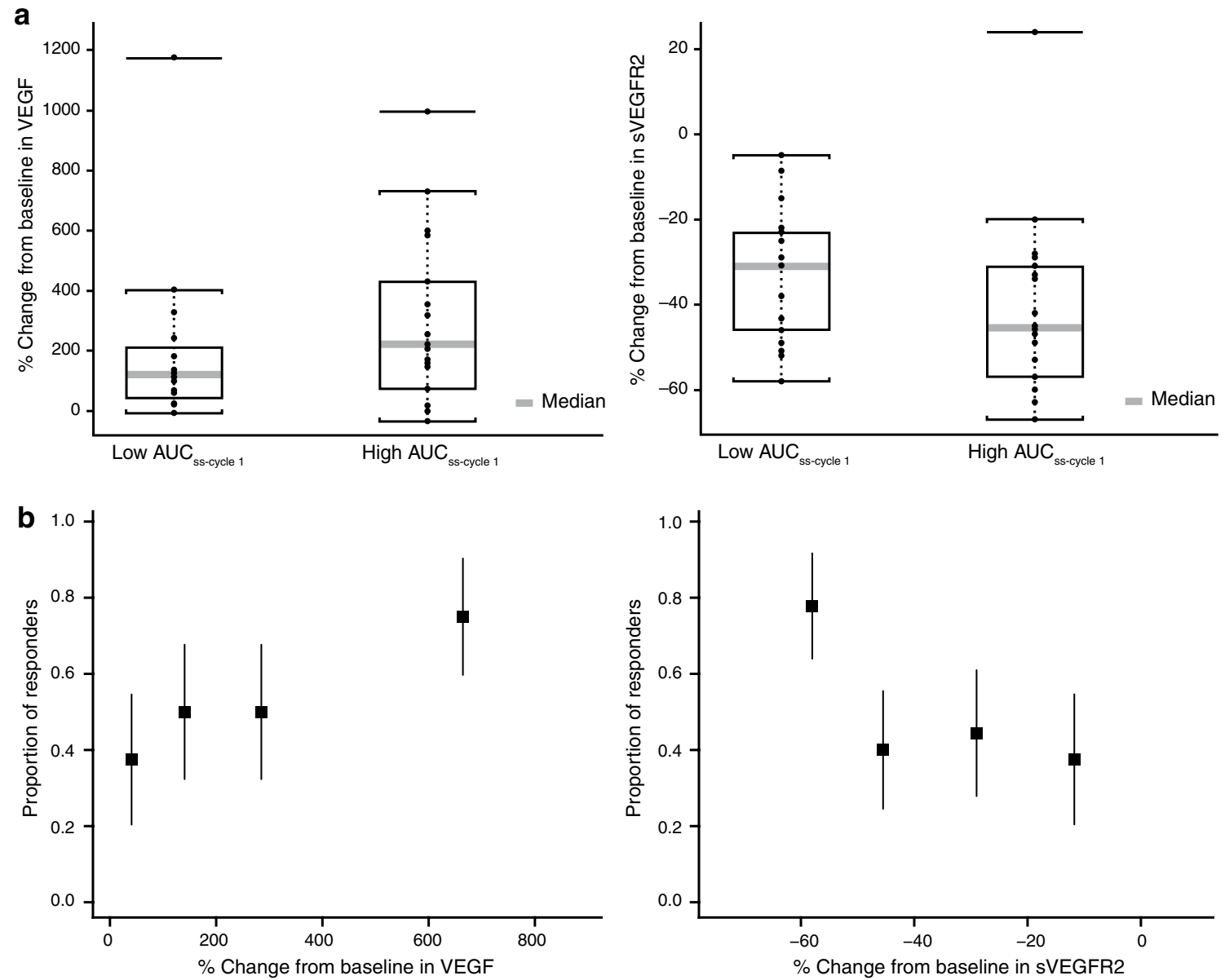

Fig. 4 a Greatest percent change from baseline per patient at any time during the study in vascular endothelial growth factor (VEGF) and soluble VEGF receptor 2 (sVEGFR2) in patients with high $\left(\geq \mathrm{mAUC}_{\mathrm{ss}-\mathrm{cycle} 1}\right)$ and low $\left(<\mathrm{mAUC}_{\mathrm{ss}-\mathrm{cycle} 1}\right)$ exposure to axitinib, and

b proportion of patients with investigator-assessed partial responses in quartiles grouped according to change from baseline in soluble proteins. $\mathrm{mAUC}_{\mathrm{ss}-\mathrm{cycle}}$, median area under the plasma concentrationtime curve at steady-state during cycle 1 
$\mathrm{BP}$ assessment is warranted. Larger randomized trials are necessary to confirm the role of axitinib for the treatment of advanced thyroid cancer.

Acknowledgments This study was supported by Pfizer Inc. Medical writing support was provided by Lilliam Poltorack, PharmD, and Joanna Bloom, PhD, at Engage Scientific Solutions and was funded by Pfizer Inc.

Conflict of interest Dr. Ingrosso, Dr. Pithavala, and Dr. Bycott are employees of and own stock in Pfizer Inc. Dr. Tortorici, an employee of Pfizer at the time this manuscript was developed, is currently an employee of CSL Behring and owns stock in Pfizer Inc. Dr. Kim, an employee of Pfizer at the time this manuscript was developed, is currently an employee of MiRNA Therapeutics and owns stock in Pfizer Inc and MiRNA Therapeutics. Dr. Cohen is a member of the speakers bureau for AstraZeneca and a consultant for Exelixis, Inc and Bayer Corporation.

Open Access This article is distributed under the terms of the Creative Commons Attribution License which permits any use, distribution, and reproduction in any medium, provided the original author(s) and the source are credited.

\section{References}

1. Ferlay J, Shin HR, Bray F, Forman D, Mathers C, Parkin DM (2010) Estimates of worldwide burden of cancer in 2008: GLOBOCAN 2008. Int J Cancer 127(12):2893-2917

2. Kilfoy BA, Zheng T, Holford TR, Han X, Ward MH, Sjodin A, Zhang Y, Bai Y, Zhu C, Guo GL, Rothman N, Zhang Y (2009) International patterns and trends in thyroid cancer incidence, 1973-2002. Cancer Causes Control 20(5):525-531

3. La Vecchia C, Bosetti C, Lucchini F, Bertuccio P, Negri E, Boyle P, Levi F (2010) Cancer mortality in Europe, 20002004, and an overview of trends since 1975. Ann Oncol 21(6): $1323-1360$

4. Simard EP, Ward EM, Siegel R, Jemal A (2012) Cancers with increasing incidence trends in the United States: 1999 through 2008. CA Cancer J Clin 62(2):118-128. doi:10.3322/caac.20141

5. Klein M, Picard E, Vignaud JM, Marie B, Bresler L, Toussaint B, Weryha G, Duprez A, Leclere J (1999) Vascular endothelial growth factor gene and protein: strong expression in thyroiditis and thyroid carcinoma. J Endocrinol 161(1):41-49

6. Gupta-Abramson V, Troxel AB, Nellore A, Puttaswamy K, Redlinger M, Ransone K, Mandel SJ, Flaherty KT, Loevner LA, O'Dwyer PJ, Brose MS (2008) Phase II trial of sorafenib in advanced thyroid cancer. J Clin Oncol 26(29):4714-4719

7. Kloos RT, Ringel MD, Knopp MV, Hall NC, King M, Stevens R, Liang J, Wakely PE Jr, Vasko VV, Saji M, Rittenberry J, Wei L, Arbogast D, Collamore M, Wright JJ, Grever M, Shah MH (2009) Phase II trial of sorafenib in metastatic thyroid cancer. J Clin Oncol 27(10):1675-1684

8. Ahmed M, Barbachano Y, Riddell A, Hickey J, Newbold KL, Viros A, Harrington KJ, Marais R, Nutting CM (2011) Analysis of the efficacy and toxicity of sorafenib in thyroid cancer: a phase II study in a UK based population. Eur J Endocrinol 165(2):315-322

9. Lam ET, Ringel MD, Kloos RT, Prior TW, Knopp MV, Liang J, Sammet S, Hall NC, Wakely PE Jr, Vasko VV, Saji M, Snyder PJ, Wei L, Arbogast D, Collamore M, Wright JJ, Moley JF, Villalona-Calero MA, Shah MH (2010) Phase II clinical trial of sorafenib in metastatic medullary thyroid cancer. J Clin Oncol 28(14):2323-2330
10. Schneider TC, Abdulrahman RM, Corssmit EP, Morreau H, Smit JW, Kapiteijn E (2012) Long-term analysis of the efficacy and tolerability of sorafenib in advanced radio-iodine refractory differentiated thyroid carcinoma: final results of a phase II trial. Eur J Endocrinol 167(5):643-650

11. Brose MS, Nutting CM, Jarzab B, Elisei R, Siena S, Bastholt L, de la Fouchardiere C, Pacini F, Paschke R, Shong YK, Sherman SI, Smit JW, Chung J, Kappeler C, Pena C, Molnar I, Schlumberger MJ (2014) Sorafenib in radioactive iodine-refractory, locally advanced or metastatic differentiated thyroid cancer: a randomised, double-blind, phase 3 trial. Lancet. doi:10.1016/ S0140-6736(14)60421-9

12. Carr LL, Mankoff DA, Goulart BH, Eaton KD, Capell PT, Kell EM, Bauman JE, Martins RG (2010) Phase II study of daily sunitinib in FDG-PET-positive, iodine-refractory differentiated thyroid cancer and metastatic medullary carcinoma of the thyroid with functional imaging correlation. Clin Cancer Res 16(21):5260-5268

13. Cohen E, Kanagarajan J, Kunnavakkam R, Needle B, Ivy P, Vokes E (2009) Sunitinib in patients with radioactive iodine refractory and progressive differentiated thyroid cancer: a phase 2 study [abstr 051]. In: World Congress on Thyroid Cancer (WCTC), Toronto, Canada, 6-10 August 2009, p 051

14. De Souza JA, Busaidy N, Zimrin A, Seiwert TY, Villaflor VM, Poluru KB (2010) Phase II trial of sunitinib in medullary thyroid cancer (MTC). J Clin Oncol 28(15s): abstr 5504

15. Locati LD, Licitra L, Agate L, Ou SH, Boucher A, Jarzab B, Qin S, Kane MA, Wirth LJ, Chen C, Kim S, Ingrosso A, Pithavala YK, Bycott P, Cohen EE (2014) Treatment of advanced thyroid cancer with axitinib: phase 2 study with pharmacokinetic/ pharmacodynamic and quality-of-life assessments. Cancer. doi: $10.1002 / \mathrm{cncr} .28766$

16. Cohen EE, Rosen LS, Vokes EE, Kies MS, Forastiere AA, Worden FP, Kane MA, Sherman E, Kim S, Bycott P, Tortorici M, Shalinsky DR, Liau KF, Cohen RB (2008) Axitinib is an active treatment for all histologic subtypes of advanced thyroid cancer: results from a phase II study. J Clin Oncol 26(29):4708-4713

17. Wells SA Jr, Robinson BG, Gagel RF, Dralle H, Fagin JA, Santoro M, Baudin E, Elisei R, Jarzab B, Vasselli JR, Read J, Langmuir P, Ryan AJ, Schlumberger MJ (2012) Vandetanib in patients with locally advanced or metastatic medullary thyroid cancer: a randomized, double-blind phase III trial. J Clin Oncol 30(2):134-141

18. Leboulleux S, Bastholt $\mathrm{L}$, Krause $\mathrm{T}$, de la Fouchardiere $\mathrm{C}$, Tennvall J, Awada A, Gomez JM, Bonichon F, Leenhardt L, Soufflet C, Licour M, Schlumberger MJ (2012) Vandetanib in locally advanced or metastatic differentiated thyroid cancer: a randomised, double-blind, phase 2 trial. Lancet Oncol 13(9):897-905

19. Bible KC, Suman VJ, Molina JR, Smallridge RC, Maples WJ, Menefee ME, Rubin J, Sideras K, Morris JC 3rd, McIver B, Burton JK, Webster KP, Bieber C, Traynor AM, Flynn PJ, Goh BC, Tang H, Ivy SP, Erlichman C (2010) Efficacy of pazopanib in progressive, radioiodine-refractory, metastatic differentiated thyroid cancers: results of a phase 2 consortium study. Lancet Oncol 11(10):962-972

20. Schlumberger MJ, Elisei R, Bastholt L, Wirth LJ, Martins RG, Locati LD, Jarzab B, Pacini F, Daumerie C, Droz JP, Eschenberg MJ, Sun YN, Juan T, Stepan DE, Sherman SI (2009) Phase II study of safety and efficacy of motesanib in patients with progressive or symptomatic, advanced or metastatic medullary thyroid cancer. J Clin Oncol 27(23):3794-3801

21. Sherman SI, Wirth LJ, Droz JP, Hofmann M, Bastholt L, Martins RG, Licitra L, Eschenberg MJ, Sun YN, Juan T, Stepan DE, Schlumberger MJ (2008) Motesanib diphosphate in progressive differentiated thyroid cancer. N Engl J Med 359(1):31-42 
22. Cabanillas ME, Brose MS, Ramies DA, Lee Y, Miles D, Sherman SI (2012) Antitumor activity of cabozantinib (XL184) in a cohort of patients (pts) with differentiated thyroid cancer (DTC). Paper presented at the American Society of Clinical Oncology (ASCO), Chicago, IL, USA, 1-5 June

23. Kurzrock R, Sherman SI, Ball DW, Forastiere AA, Cohen RB, Mehra R, Pfister DG, Cohen EE, Janisch L, Nauling F, Hong DS, Ng CS, Ye L, Gagel RF, Frye J, Muller T, Ratain MJ, Salgia R (2011) Activity of XL184 (Cabozantinib), an oral tyrosine kinase inhibitor, in patients with medullary thyroid cancer. J Clin Oncol 29(19):2660-2666

24. Elisei R, Schlumberger MJ, Muller SP, Schoffski P, Brose MS, Shah MH, Licitra L, Jarzab B, Medvedev V, Kreissl MC, Niederle B, Cohen EE, Wirth LJ, Ali H, Hessel C, Yaron Y, Ball D, Nelkin B, Sherman SI (2013) Cabozantinib in progressive medullary thyroid cancer. J Clin Oncol 31(29):3639-3646. doi:10.1200/ JCO.2012.48.4659

25. Schlumberger M, Jarzab B, Cabanillas ME, Robinson B, Pacini F, Ball DW, McCaffrey JC (2012) A phase II trial of the multitargeted kinase inhibitor lenvatinib (E7080) in advanced medullary thyroid cancer (MTC). In: American Society of Clinical Oncology (ASCO), Chicago, IL, USA, 1-5 June 2012. J Clin Oncol, p 5591

26. Hu-Lowe DD, Zou HY, Grazzini ML, Hallin ME, Wickman GR, Amundson K, Chen JH, Rewolinski DA, Yamazaki S, Wu EY, McTigue MA, Murray BW, Kania RS, O'Connor P, Shalinsky DR, Bender SL (2008) Nonclinical antiangiogenesis and antitumor activities of axitinib (AG-013736), an oral, potent, and selective inhibitor of vascular endothelial growth factor receptor tyrosine kinases 1, 2, 3. Clin Cancer Res 14(22):7272-7283

27. Pfizer Inc (2012) Inlyta $^{\circledR}$ (axitinib) prescribing information. Pfizer Inc. http://labeling.pfizer.com/ShowLabeling.aspx?id=759. Accessed 13 Nov 2013

28. Therasse P, Arbuck SG, Eisenhauer EA, Wanders J, Kaplan RS, Rubinstein L, Verweij J, Van Glabbeke M, van Oosterom AT, Christian MC, Gwyther SG (2000) New guidelines to evaluate the response to treatment in solid tumors. European Organization for Research and Treatment of Cancer, National Cancer Institute of the United States, National Cancer Institute of Canada. J Natl Cancer Inst 92(3):205-216

29. National Cancer Institute Division of Cancer Treatment and Diagnosis (2006) Cancer therapy evaluation program. Common
Terminology Criteria for Adverse Events, Version 3.0. DCTD, NCI, NIH, DHHS. http://ctep.cancer.gov/protocolDevelopment/ electronic_applications/docs/ctcaev3.pdf. Accessed 13 Nov 2013

30. Pithavala YK, Tong W, Mount J, Rahavendran SV, Garrett M, Hee B, Selaru P, Sarapa N, Klamerus KJ (2010) Effect of ketoconazole on the pharmacokinetics of axitinib in healthy volunteers. Invest New Drugs 30(1):273-281

31. Pithavala YK, Tortorici M, Toh M, Garrett M, Hee B, Kuruganti U, Ni G, Klamerus KJ (2010) Effect of rifampin on the pharmacokinetics of axitinib (AG-013736) in Japanese and Caucasian healthy volunteers. Cancer Chemother Pharmacol 65(3):563-570

32. Tortorici MA, Toh M, Rahavendran SV, Labadie RR, Alvey CW, Marbury T, Fuentes E, Green M, Ni G, Hee B, Pithavala YK (2011) Influence of mild and moderate hepatic impairment on axitinib pharmacokinetics. Invest New Drugs 29(6):1370-1380

33. Simon R (1989) Optimal two-stage designs for phase II clinical trials. Control Clin Trials 10(1):1-10

34. National Comprehensive Cancer Network Inc (2013) 2013 practice guidelines in oncology-thyroid carcinoma, v.2. http://www. nccn.org/professionals/physician_gls/f_guidelines.asp. Accessed 13 Nov 2013

35. Pacini F, Castagna MG, Brilli L, Pentheroudakis G (2012) Thyroid cancer: ESMO clinical practice guidelines for diagnosis, treatment and follow-up. Ann Oncol 23(Suppl 7):vii110-119

36. Bass MB, Sherman SI, Schlumberger MJ, Davis MT, Kivman L, Khoo HM, Notari KH, Peach M, Hei YJ, Patterson SD (2010) Biomarkers as predictors of response to treatment with motesanib in patients with progressive advanced thyroid cancer. J Clin Endocrinol Metab 95(11):5018-5027

37. Rini BI, Garrett M, Poland B, Dutcher JP, Rixe O, Wilding G, Stadler WM, Pithavala YK, Kim S, Tarazi J, Motzer RJ (2013) Axitinib in metastatic renal cell carcinoma: results of a pharmacokinetic and pharmacodynamic analysis. J Clin Pharmacol 53(5):491-504

38. Lu JF, Claret L, Sutjandra L, Kuchimanchi M, Melara R, Bruno R, Sun YN (2010) Population pharmacokinetic/pharmacodynamic modeling for the time course of tumor shrinkage by motesanib in thyroid cancer patients. Cancer Chemother Pharmacol 66(6):1151-1158 